\title{
Partha Kar: What will come after the covid-19 crisis?
}

\author{
Partha Kar consultant in diabetes and endocrinology \\ Portsmouth Hospitals NHS Trust
}

As we enter deeper into the covid-19 lockdown there's a confused smog of data, speculation, and media hunger for news of anything that may be deemed controversial. Some clarity does seem to be emerging, however, alongside questions about what will have changed when the current crisis passes.

For example, there are disparities in the people affected. Figures show a higher proportion from ethnic minorities being admitted to intensive care units with covid-19. Of course, we must consider the baseline population of different areas when we interpret these figures. But there's a growing feeling that, while cultural habits and clustering of families may have a bearing on the situation, these figures also reflect social economic disparities.

We should hope that, once the current crisis is over, these data open up a wider conversation about disparities and healthcare.

But we shouldn't forget that the high levels of maternal mortality in ethnic minorities have been known for years, and the healthcare system has been either unable or unwilling to tackle them.

The expansion in use of digital technology during this crisis has also been fascinating. The fact that people are using it more isn't surprising. What is, however, is the belief among many doctors and others in the healthcare system that, once the immediate covid-19 crisis has passed, this technology will become part and parcel of how the system works. We shall see.

We mustn't forget that, while the NHS prides itself on providing equal access for everyone, the benefits of many digital innovations are skewed towards people from higher socioeconomic groups. In the digital world, alongside the genuine offers of philanthropy during the pandemic I've also seen some cynical pushing through of products that either don't work or have little to no evidence to support their use. A crisis creates opportunities, and not necessarily just for people with the best motivations.
One big concern throughout discussions of our approach to tackling covid-19 has been the overall impact of measures taken to control its spread, especially on people whose care has been put on "pause." In the world of diabetes we're attempting to run two key areas: services for pregnant women, and foot care-the latter because of its nature and its implications for the individual. Much of diabetes care has focused on supporting people with their self-management. But, if you're worried about how to put food on the table for your kids, catching up on online self-management advice will be some way down the pecking order.

Many clinical services are trying to run as many things virtually as they can, but these are untested areas, without much evidence that they actually benefit the user-or whether they continue to deliver care, improve it, or create any impression of normality. Once the crisis is over a large effort will be needed to pick up the pieces, with justifiable concern in areas such as cancer care. Covid-19 has paused many lives, but the incremental progression of pathologies doesn't offer any such breaks. A six month "hiatus" may not seem huge in chronic conditions, but in areas such as dialysis or progression of foot pathologies it raises concern about the effects of this crisis. What will the overall impact be? Time will tell.

For the moment, however, the message is the same: stay at home, help the NHS, and save lives. A key focus should also be ensuring that we evaluate rationally what may or may not be evidence based use of public money-perhaps to be in even sharper focus, with an expected downturn of the economy. The future is what we must start working on, hopefully soon.

Competing interests: www.bmj.com/about-bmj/freelance-contributors

Provenance and peer review: Commissioned; not externally peer reviewed.

Published by the BMJ Publishing Group Limited. For permission to use (where not already granted under a licence) please go to http://group.bmj.com/group/rights-licensing/ permissions 